\title{
Determination Method of Centerpost Distance of Interior Permanent Magnet Synchronous Motor for Electric Vehicle Traction Motor considering Mechanical Safety
}

\author{
Sung-Jin Kim *, Yong-Jae Kim *, Sang-Yong Jung** and Kenji Suzuki***
}

\begin{abstract}
With the active development of hybrid electric vehicle (HEV), the application of interior permanent magnet synchronous motor (IPMSM) has been expanded. As wide driving region of IPMSM for electric vehicle (EV) traction motor is required, many studies are conducted to improve characteristics of a motor in both low and high-speed driving regions. A motor in high-speed driving region generates (produces) large stress to the rotor. Thus, the rotor needs to be designed considering the mechanical safety. Therefore, in this paper, we conducted stress analysis and electromagnetic analysis to determine the centerpost's distance which is considered important during the design of IPMSM for EV traction motor in order to secure mechanical safety and satisfy specifications of output requirement.
\end{abstract}

Keywords: IPMSM, SPMSM, Centerpost, Bridge, Cogging torque, Torque ripple, Centrifugal force, Electromagnetic analysis, Stress analysis, Finite element analysis (FEA)

\section{Introduction}

Recently, vehicles using fossil fuels have been changed to eco-friendly futuristic vehicles using electrical energy in response to the concern of the environmental problems such as global warming [1-2]. As the energy source of ecofriendly vehicles has been changed to electrical energy from fossil fuels, their driving gear has replaced the engine with motor [3-4]. The motor in driving motor for electric vehicles was used at the similar rate to the induction motor and interior permanent magnet synchronous motor (IPMSM), but since the development of hybrid electric vehicle (HEV) became active, IPMSM was mainstreamed [5-7].

Regarding an IPMSM, centerpost or bridge may be broken by centrifugal force caused by high-speed driving according to the demand for high efficiency. Therefore, the exact stress analysis is required and it needs to design a rotor's structure to secure sufficient safety factor. With respect to structure design of rotor, centerpost's distance in magnet position arrangement is one of factors influencing operation characteristics. When distance of centerpost is

\footnotetext{
* Dept. of Electrical Engineering, Chosun University, Gwang-ju, Korea. ( kimyj21@chosun.ac.kr)

** School of Information and Communication Engineering, Sungkyunkwan University, Suwon, Korea.

** Dept. of Electrical and Electronic Engineering, Tokyo City University, Tokyo, Japan.

Received 02 February 2013 ; Accepted 20 February 2013
}

narrow, magnetic flux created by rotor magnet is toward air gap so that contributes to torque and improves performance of motor. However, when the distance is wide, magnetic flux in rotor magnet is not delivered to the stator by passing through the air gap but rather it circles inside the rotor not contributing to the motor output [8-10].

Therefore, in this paper, moved magnet and the whole air-barrier to adjust the distance of centerpost of IPMSM and the characteristics resulted by this adjustment of the distance have been analyzed using the 2-D numerical analysis. Moreover, we conducted stress analysis to decide the optimum distance of centerpost securing mechanical safety and satisfy specifications of output required.

\section{The Shape and Specifications of IPMSM}

This study conducted electromagnetic analysis and stress analysis to decide centerpost's distance which is considered important in designing IPMSM. The specifications of IPMSM are as shown in Table 1. In the analysis model of this paper, IPMSM requires high starting torque and a driving performance of wide speed region. As the driving speed region for IPMSM of EV traction motor is reaching higher gradually, a motor with a driving speed of 18000 rpm is on the way of development. In this study, we have selected the motor with a maximum speed of $14500 \mathrm{rpm}$ as the speed based on loading of stress analysis. In addition, 
the characteristics of electromagnetic analysis were also compared at maximum speed. The cross-sectional diagram of 2-D numerical analysis IPMSM is shown in Fig.1.

Table 1. The specifications of IPMSM

\begin{tabular}{|c|c|c|c|}
\hline \multicolumn{3}{|c|}{ Parameter } & Value (Unit) \\
\hline \multirow{5}{*}{ Rotor } & \multicolumn{2}{|c|}{ Magnet type } & Nd-Fe-B \\
\hline & \multicolumn{2}{|c|}{ Number of poles } & 8 (Poles) \\
\hline & \multirow{3}{*}{$\begin{array}{c}\text { Silicon } \\
\text { steel }\end{array}$} & Material & $35 \mathrm{PN} 210$ \\
\hline & & Thickness & $0.35(\mathrm{~T})$ \\
\hline & & Yield strength & $440(\mathrm{Mpa})$ \\
\hline \multirow{5}{*}{ Stator } & \multicolumn{2}{|c|}{ Phase } & 3 \\
\hline & \multicolumn{2}{|c|}{ Number of slots } & 36 \\
\hline & \multicolumn{2}{|c|}{ Winding } & Distributed \\
\hline & \multirow{2}{*}{$\begin{array}{l}\text { Silicon } \\
\text { steel }\end{array}$} & Material & $35 \mathrm{PN} 210$ \\
\hline & & Thickness & $0.35(\mathrm{~T})$ \\
\hline & \multicolumn{2}{|c|}{ Maximum speed } & $14,500(\mathrm{rpm})$ \\
\hline
\end{tabular}

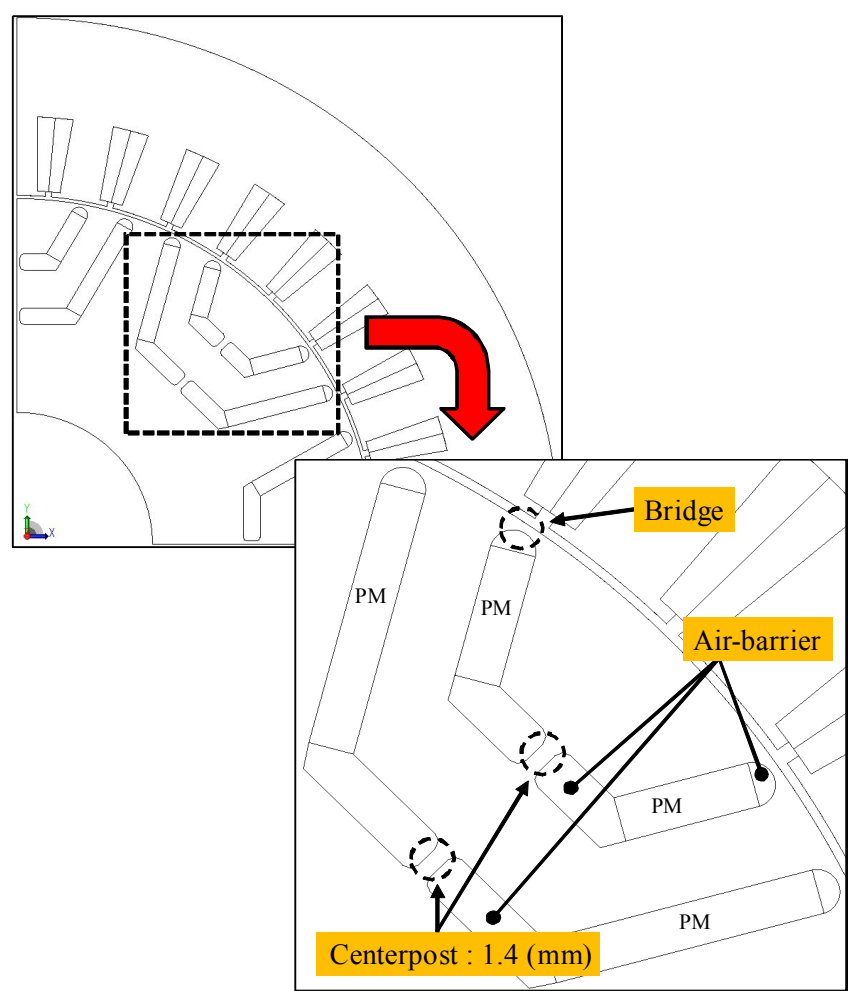

Fig. 1. The cross-sectional diagram of 2-D numerical analysis IPMSM

Basically, motor can generate torque when magnetic flux created in rotor and stator pass through the air gap and achieves linkage. If the magnetic flux created in stator and rotor doesn't achieve linkage, it is regarded as leakage of components so the motor gets loss. If centerpost or bridge part is not saturated, magnetic flux created in magnet of rotor is not delivered to rotor through passing through air gap but it circles in rotor and doesn't contribute to the motor output at all. Therefore, this type of magnet position structure, the distances of both the centerpost and bridge must be narrowed down at most, the magnet flux must also be minimized, and make the remaining component direct toward the air gap in order to contribute to the torque.

However, the distance of centerpost has a limit of narrowing due to yield strength of rotor core material. To determine such a limit, we performed the electromagnetic analysis and the stress analysis by adjusting the centerpost distance of basic model from $1.4 \mathrm{~mm}$ up to $0.2 \mathrm{~mm}$ at the interval of $0.2 \mathrm{~mm}$.

\section{Electromagnetic Analysis Result according to the Distance Adjustment of Centerpost}

Fig. 2 represents the magnetic flux density contour according to the distance adjustment of centerpost. Fig. 2 (a) shows the magnetic flux density contour of the basic model with the centerpost's distance of $1.4 \mathrm{~mm}$, while Fig 2 (b) represents the magnetic flux density contour with the distance of $0.2 \mathrm{~mm}$. As shown in Fig. 2, we can observe that the saturation degree of magnetic flux at the centerpost is stronger when the distance of centerpost is shorter. In case of the basic model, the maximum magnetic flux density reached 2.01 T. However, in case of the model with the centerpost's distance of $0.2 \mathrm{~mm}$, the maximum magnetic flux density reached $2.13 \mathrm{~T}$.

\subsection{Cogging torque}

Fig. 3 shows the cogging torque change according to the distance of centerpost. By the combination of both pole and slot numbers, each mechanical angle $5^{\circ}$ shows a repeated waveform. The cogging torque waveforms according to the distance of centerpost are shown in Fig. 3(a), the cogging torque pulsation is shown in Fig. 3(b). As shown in Fig. 3, cogging torque reached the highest point when the centerpost was at the shortest point with the distance of 0.2 $\mathrm{mm}$. The maximum cogging torque in this case was 0.95 $\mathrm{Nm}, 2.03 \mathrm{Nm}$ peak to peak and the peak average $2.8 \%$. Thus, it was verified that the cogging torque increases more when the distance of centerpost becomes shorter.

\subsection{Torque}

Fig. 4 shows torque change according to the distance of centerpost. Fig. 4 (a) shows the torque waveforms 
according to the distance of centerpost. Fig. 4 (b) shows both the average and the maximum torques according to the

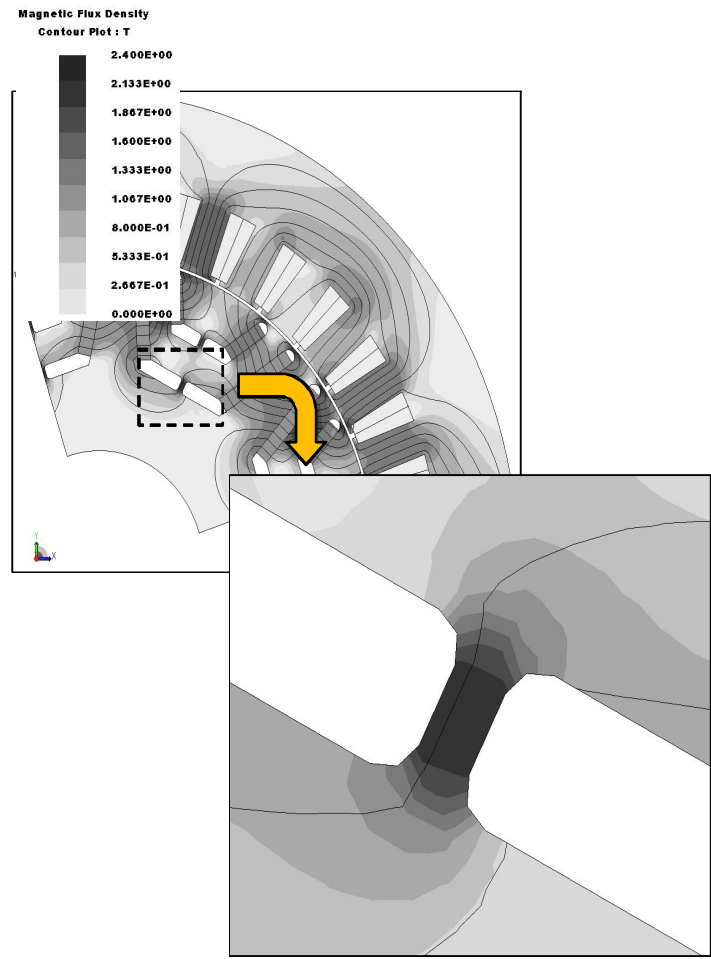

(a)

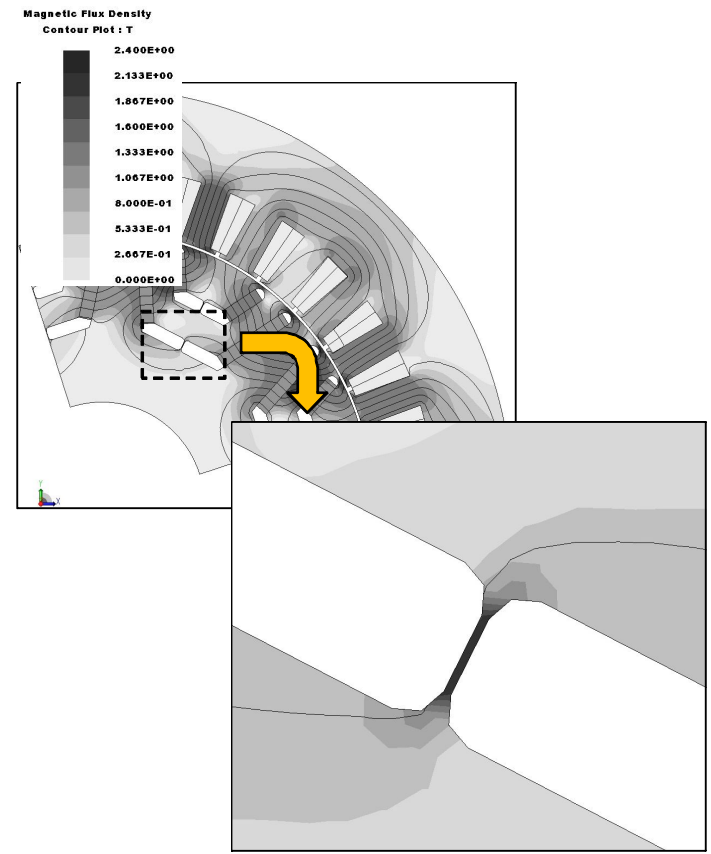

(b)

Fig. 2. Magnetic flux density contour according to the distance adjustment of centerpost (a) Distance of centerpost : $1.4(\mathrm{~mm})$ (b) Distance of centerpost : $0.2(\mathrm{~mm})$

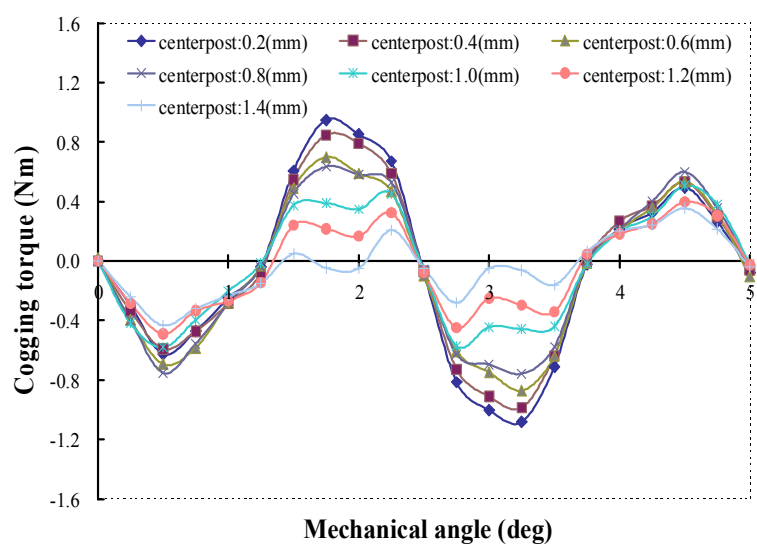

(a)

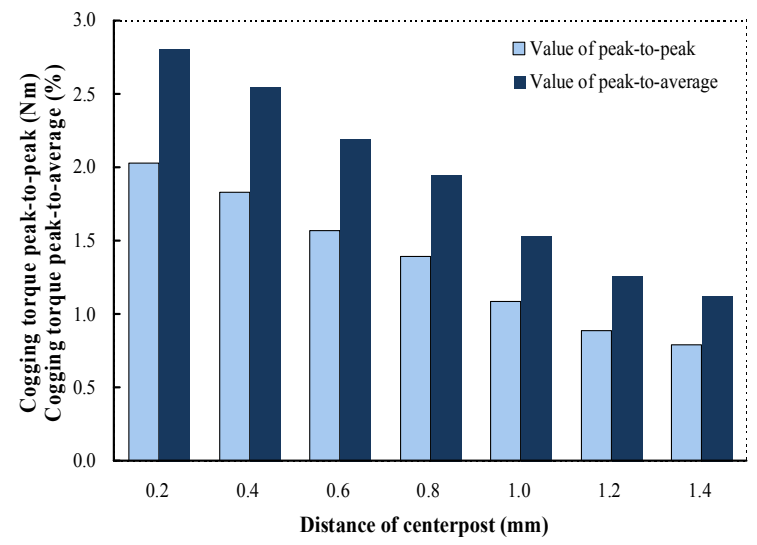

(b)

Fig. 3. Cogging torque changes according to the distance adjustment of centerpost (a) Cogging torque waveforms (b) Cogging torque pulsation

distance of the centerpost and the torque ripple. And according to the distance of centerpost, these are shown in Fig. 4 (c). As shown in Fig. 4, both the average torque and maximum torque were generated at most when the distance of centerpost was at the shortest point. Thus, the shorter the distance of centerpost, the more torque was generated. When the standard distance of centerpost was adjusted from $1.4 \mathrm{~mm}$ to $0.2 \mathrm{~mm}$, the maximum torque was increased by 4 $\mathrm{Nm}$ and the average torque was increased by $2 \mathrm{Nm}$.

However, the shorter the distance of centerpost, the more torque ripple was generated. When the centerpost's distance was $1.4 \mathrm{~mm}$ and torque ripple was $6.9 \%$. When the distance was adjusted to $0.2 \mathrm{~mm}, 10.2 \%$ of torque ripple was generated which was an increase of $3.3 \%$ only.

From the result above, we can observe that the torque and the torque ripple increases when the distance of centerpost becomes shorter. 


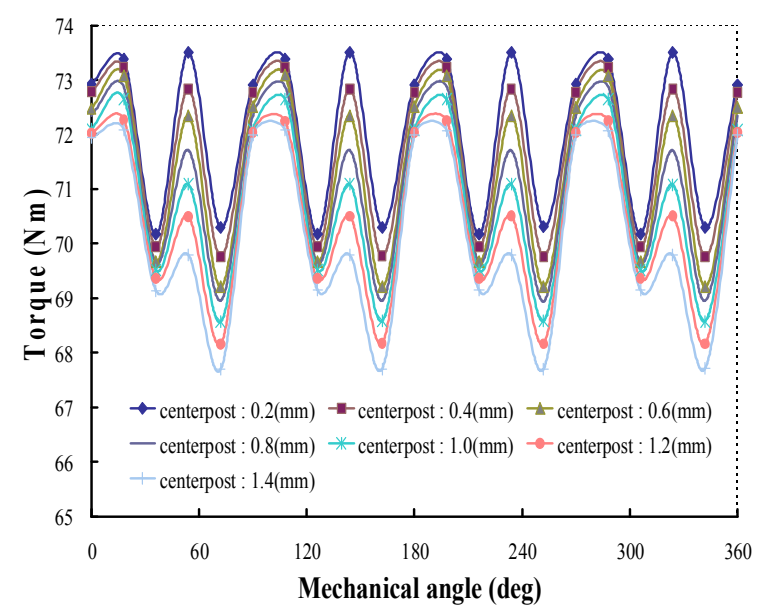

(a)

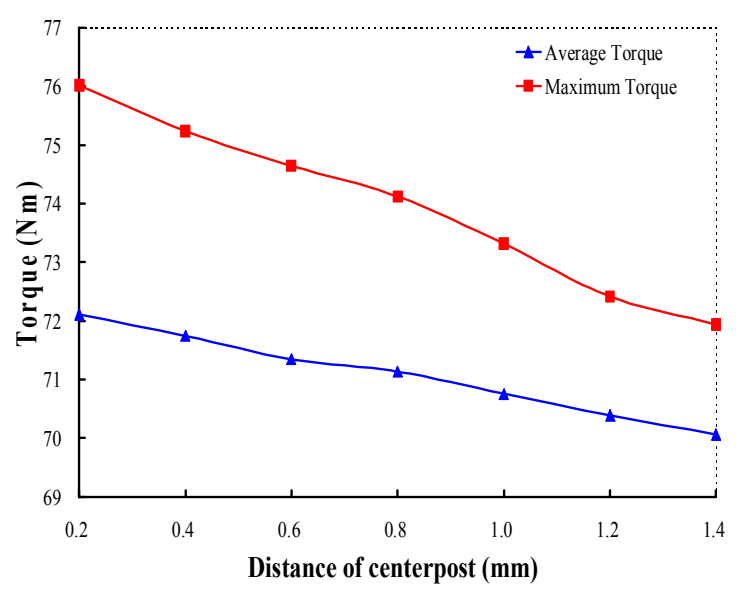

(b)

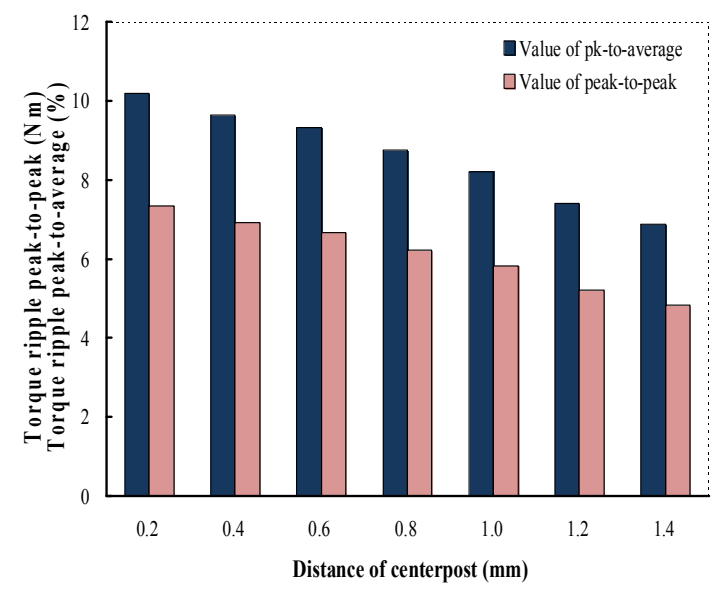

(c)

Fig. 4. Torque changes according to the distance adjustment of centerpost (a) Torque waveforms (b) The average and the maximum Torque (c) Torque ripple

\section{Stress Analysis Result according to the Distance Adjustment of Centerpost}

In order to examine the mechanical safety of IPMSM during maximum speed driving, we've performed stress analysis using models with adjusted distance of Centerpost where the maximum torque is generated.

Considering the material properties value, the stress analysis has been performed under the static load condition which functions when it is driven constantly with the maximum speed of $14500 \mathrm{rpm}$. Fig. 5 shows the stress contour of IPMSM obtained through the stress analysis. Fig. 5 (a) indicates the stress contour of basic model with the centerpost's distance of $1.4 \mathrm{~mm}$. The stress contour of model with the centerpost's distance of $0.2 \mathrm{~mm}$ is shown in Fig. 5 (b). In Fig. 5, we can observe that the stress is concentrated at the centerpost. The changes of maximum stress and safety factor according to the distance of centerpost are shown in Fig. 6. As shown in Fig. 6, the maximum stress(Von-Mises stress standard) was generated as $473.487 \mathrm{Mpa}$ in $0.2 \mathrm{~mm}$ of centerpost. This means that this value is higher than 440 Mpa yield strength of silicon steel lamination (35PN210) used in rotor, so rotor may be destroyed.

Its safety factor, which recorded 0.93 , fell short of one of stable general electrical machinery. For this reason, given the electromagnetic characteristics, it would be better to select $0.2 \mathrm{~mm}$ in terms of centerpost distance, but if structural characteristics are also taken into account, it is safer to select $0.6 \mathrm{~mm}$, a figure whose safety factor is $1.3 \sim 1.5$. Although this study doesn't suggest, it's necessary to apply dynamic load conditions through operating/static test among durability tests of motor to select the distance of centerpost by considering fatigue cycle of motor by time.

\section{Conclusion}

This study carried out electromagnetic analysis and stress analysis by using finite element method(FEM) among numerical analysis according to distance of centerpost in high-speed driving region. As the result, it was confirmed through the electromagnetic analysis that the operation characteristics of motor were improved at most when the distance of centerpost was the narrowest. Though the torque ripple increased a little when the distance of centerpost became narrower, both the average torque and maximum torque, increased by $6 \%$ when the distance of centerpost was adjusted. In addition, the stress analysis showed the optimum length, the structural limit of centerpost distance 
by examining stress of centerpost. This result can be used as the standard value for magnet alignment of motor's rotor. A more improved and advanced design technology of motor could be expected if the findings of this study are combined with the optimum design.

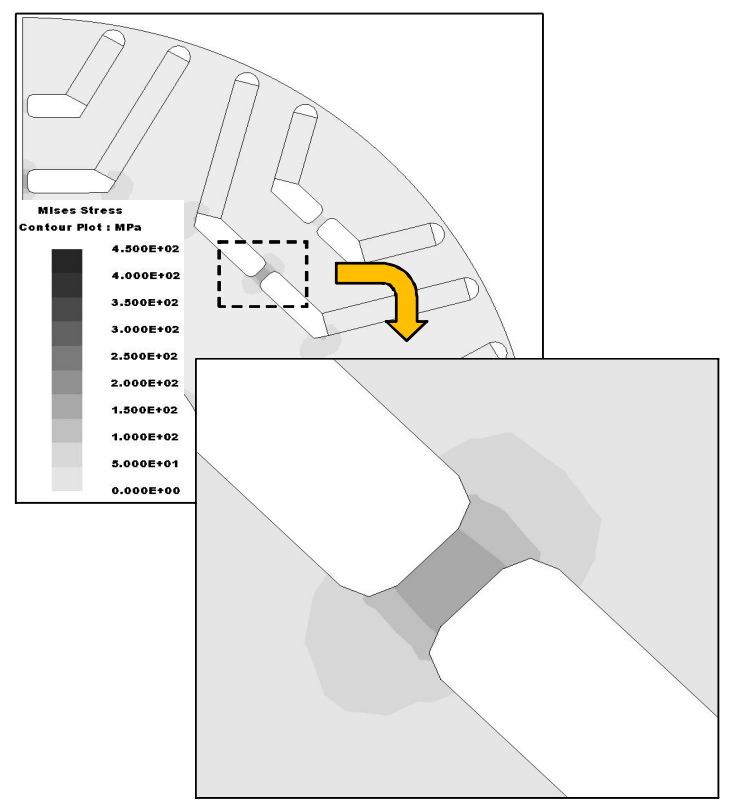

(a)

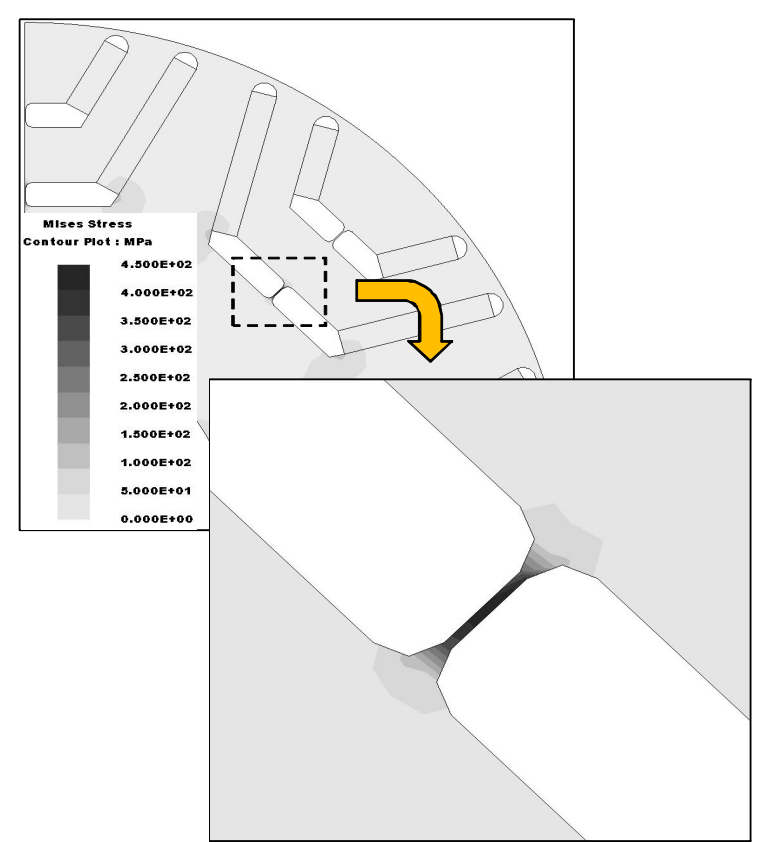

(b)

Fig. 5. The stress contour of IPMSM with the maximum speed of $14500 \mathrm{rpm}$ (a) Distance of centerpost : 1.4 (mm) (b) Distance of centerpost : 0.2 (mm)

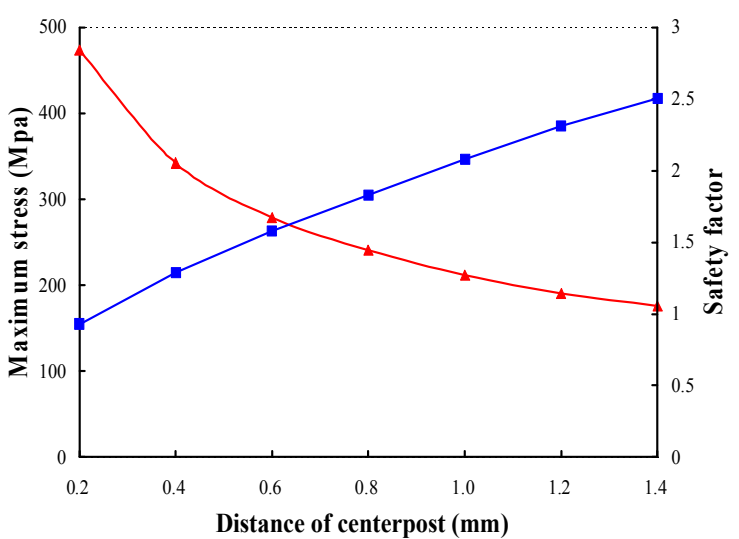

Fig. 6. The stress contour of IPMSM with the maximum speed of $14500 \mathrm{rpm}$

\section{References}

[1] Z. Q. Zhu, David Howe, "Influence of Design Parameter on Cogging Torque in Permanent Magnet Machines, IEEE Trans. Energy Conv., vol. 15, no. 4, 2000.

[2] Gulez K., Adam A.A., Pastaci H., "A Novel Direct Torque Control Algorithm for IPMSM With Minimum Harmonics and Torque Ripples", IEEE/ASME Trans. Mechatronics, vol. 12, no, 2, pp. 223-227, 2007.

[3] E. C. Lovelace, T. M. Jahns, "Mechanical Design Considerations for Conventionally-laminated, High-Speed, Interior PM Synchronous Machine Rotors", IEEE Trans. Ind. Appl., vol. 40, no. 3, pp. 806-812, 2004.

[4] Jae-Woo Jung, Byeong-Hwa Lee, Do-Jin Kim, Jung-Pyo Hong, Jae-Young Kim, Seong-Min Jeon, Do-Hoon Song, "Mechanical Stress Reduction of Rotor Core of Interior Permanent Magnet Synchronous Motor", IEEE Trans. Magnetics, vol. 48, no. 2, pp. 911-914, 2012.

[5] Ho-Kyoung Lim, Baik-Kee Song, Sung-Il Kim, Jung-Pyo Hong, "A Study on the Relation Between Rotor Rib and Maximum Power of IPMSM in Flux Weakening Region", in Conf. 2010 ICEMS Int. Conf. Electrical Machines and System, pp. 1222-1225, 2010.

[6] Seungho Lee, Yu-Seok Jeong, Yong-Jae Kim, Sang-Yong Jung, "Novel Analysis and Design Methodology of Interior Permanent-Magnet Synchronous Motor Using Newly Adopted Synthetic Flux Linkage", IEEE Trans. Ind. Electron., Vol. 58, No. 9, pp. 3806-3814, 2011.

[7] K. Yamazaki, H. Ishigami, "Rotor-Shape Optimization of Interior-Permanent-Magnet Motors to Reduce Harmonic Iron Losses", IEEE Trans. Ind. Electron., vol. 57, no. 1, pp. 61-69, 2010.

[8] D.Pavlik et al, "A Finite Element Technique for Calculating the Magnet Sizes \& Inductances of Permanent Magnet Machine", IEEE Trans. Energy Conv., vol. 3, no. 1, pp. 116$122,1998$.

[9] Yoshinari Asano, Yukio Honda, Yoji Takeda, Shigeo Morimoto, "Reduction of Vibration on Concentrated Winding Permanent Magnet Synchronous Motors with Considering Radial Stress", IEE Trans. Jpn., vol. 121-D, no. 11, pp. 1185-1191, 2001. 
[10] Sang-Yeop Kwak, Jae-Kwang Kim, Hyun-Kyo Jung, "Characteristic Analysis of Multilayer-Buried Magnet Synchronous Motor Using Fixed Permeability Method", IEEE Trans. Energy Conv., vol. 20, no. 3, pp. 549-555, 2005.

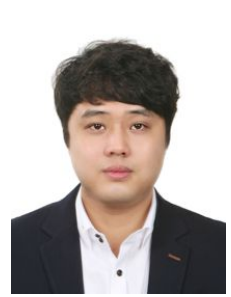

Sung-Jin Kim received B.S and M.S degree in department of electrical engineering from Chosun University, Gwang-ju, Korea in 2011 and 2013, respectively. Since 2013, he's doing a Ph.D course in department of electrical engineering from Chosun University, Gwang-ju, Korea. His research interests are numerical analysis and design of linear machineries and PM machineries.

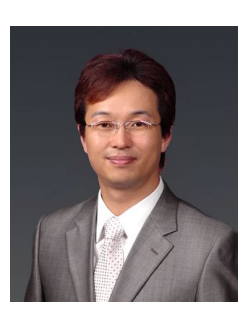

Yong-Jae Kim received B.S degree in department of electrical engineering from Chosun University Gwang-ju, Korea in 1996 and the M.S, Ph.D degree in electrical engineering from Musashi Institute of Technology, Tokyo, in 2003 and 2006, respectively. From 2006 to 2007, he was a Researcher of electrical and electronic engineering with the Musashi Institute of Technology, Tokyo, Japan. He is currently an Assistant Professor with the Department of Electrical Engineering, Chosun University, Gwangju, Korea. His current research interests include the design and analysis of electric machines.

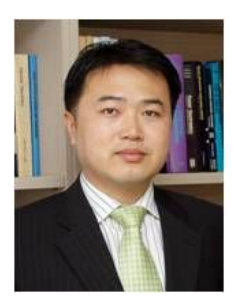

Sang-Yong Jung received the B.S., M.S., and Ph.D. degrees in electrical engineering from Seoul National University, Seoul, Korea, in 1997, 1999, and 2003, respectively. From 2003 to 2006, he was a Senior Research Engineer with the R\&D Division, Hyundai Motor Company, and Kia Motor company, Korea. From 2006 to 2011, he was an Assistant Professor with the Department of Electrical Engineering, Dong-A University, Busan, Korea. $\mathrm{He}$ is currently an Associate Professor with the School of Information and Communication Engineering, Sungkyunkwan University, Suwon, Korea. His research interests include the numerical analysis and optimal design of electric machines and power apparatus.
Kenji Suzuki received the the B.E.,M.E., and Ph.D. degrees in electrical and electronic engineering from the Musashi Institute of Technology, Tokyo, Japan, in 2005, 2007, and 2010, respectively. From 2010 to 2012, he was a Researcher with the Research and Development Headquarters, AIDA Engineering, Ltd., Sagamihara, Japan. $\mathrm{He}$ is currently a Lecturer with the Department of Electrical and Electronic Engineering, Tokyo City University, Tokyo, Japan. His current research interests include motor drives and control and analysis of linear motors. 